\title{
$\widehat{A}$ Madridge
}

madridge Journal of Women's Health and Emancipation

interconnecting Scientific World

Case Report

Open Access

\section{Vulvar Plexiform Neurofibromatosis, Case Report and Review of Literatures}

\author{
Mohamed Ibrahim Mohamed Amer* and Amal Alloob \\ Ain Shams University, Cairo, Egypt
}

\section{Article Info}

*Corresponding author:
Mohamed Ibrahim Mohamed Amer
Ain Shams University
Egypt
E-mail: mohamed_amer810@yahoo.com

Received: August 1, 2017

Accepted: August 10, 2017

Published: August 16, 2017

Citation: Amer Ml, Alloob A. Vulvar Plexiform Neurofibromatosis, Case Report and Review of Literatures. Madridge J Womens Health Emancipation. 2017; 1(1): 7-10. doi: $10.18689 /$ mjwh-1000103

Copyright: ( 2017 The Author(s). This work is licensed under a Creative Commons Attribution 4.0 International License, which permits unrestricted use, distribution, and reproduction in any medium, provided the original work is properly cited.

Published by Madridge Publishers

\begin{abstract}
Neurofibromatosis is a rare disease that can affects the female urogenital system with tumor formation. Clitoral involvement is rare and selective labium majus neurofibroma without clitoral involvement is extremely rare. Only 31 cases of genitourinary neurofibromas have been described in the literature. We report on a vulval plexiform neurofibroma of diffuse type in a child as a primary presentation of neurofibromatosis without systemic manifestations of the disease nor clitoral involvement which is extremely rare. Immunohistochemical study of the excised lesion is important to confirm the diagnosis. Neurofibroma should be considered as one of the differential diagnosis of the vulval swelling which would help in the primary surgery where extended excision of the tumor is essential. Long-term follow-up is needed where there is increased risk of recurrence and malignant transformation.
\end{abstract}

Keywords: Neurofibromatosis; Vulva; Tumor recurrence.

\section{Introduction}

Plexiform neurofibroma is one type of the generalized neurofibromatosis. It is considered to be a hamartoma rather than a typical tumor where it occurs due to overgrowth of neural tissue in the subcutaneous fat [1]. The origin of this disease was traced to a specific gene region on chromosome 17 which is autosomally dominant with variable penetration [2]. Approximately $50 \%$ of patients have a family history of the disorder; the lesions in the remainder are believed to arise from new mutations. The frequency of malignant neurogenic tumors in patients with neurofibromatosis is higher than in the general population, with rates varying from $5 \%$ to $30 \%$, however, is rare in children $[3,4]$. The disorder usually is manifested in young children by café-au-lait spots, where more than six spots are considered to be pathognomonic of the disease. Other manifestations include bone overgrowth, congenital bowing and pseudarthrosis of bone and soft tissue, kyphoscoliosis, focal gigantism, and megalencephaly $[5,6]$.

Clitoral neurofibromas in neurofibromatosis type 1 are rare. Clitoromegaly with pseudopenis is the most frequent presentation of a neurofibroma in a female, while labia majora neurofibroma without clitoral involvement is rare [7]. Less than 31 females with NF1 with external genital involvement were recorded in the literatures $[7,8]$. The treatment of plexiform neurofibromas is by surgical excision, but complete removal is difficult, being an infiltrating tumor, with an increased rate of recurrence [9]. The clinical suspicion of NF might help in the management by preventing undue procedures [10]. 


\section{Case}

Premenarchal 11 years old girl presented by her mother with a slowly growing, painless, right sided Vulval swelling of few months duration. General examination revealed complete female secondary sexual characters without any clinical evidence of neurofibromatosis and there was no enlargement of neither inguinal lymph nodes nor Liver and spleen.Local examination revealed soft subcutaneous swelling with illdefined margins of $6 \times 8 \mathrm{~cm}$ in diameters, located at right labium majus, and attached to the overlying skin without involvement of labia minora or clitoris.

Ultrasound Duplex of the mass revealed an ill-defined right vulval swelling measuring $49 \times 71 \times 30 \mathrm{~mm}$ presenting hypoechoic center with echogenic peripheral portion. The swelling is highly vascular presenting arterial channels showing low resistance flow with a peak velocity of $31 \mathrm{~cm} / \mathrm{sec}$ and multiple venous channels inside. The swelling was at first diagnosed as a case of haemangioma, lymphangioma or lipoma, and excision biopsy was decided for final diagnosis.

At the operation, the mass was found very vascular involving the epidermal and subcutaneous tissues with no line of demarcation between the mass and the surrounding apparently normal vulval tissues. Excision of the mass was done with the overlying skin to the extent that both labia majora became cosmetically of the same size. The excised mass later proved to be plexiform neurofibromatosis at histopathologic examination and confirmed by immunohistochemical study. The patient warned of the possibility of recurrence since the swelling was not completely excised with a safety margin as proved at histopathologic examination, and advised for follow up.

Four years later the patient presented with recurrence of the Vulval swelling at the same site with the same criteria of soft subcutaneous swelling with ill-defined edges and attached to the overlying skin. Skin manifestations of neurofibromatosis in the form of multiple cafe au lait spots started to be manifested on the neck, chest, abdomen and buttocks (Figure 1). Meticulous retaking of the family history proved that her father having neurofibromatosis (Von Recklinghausen's disease).

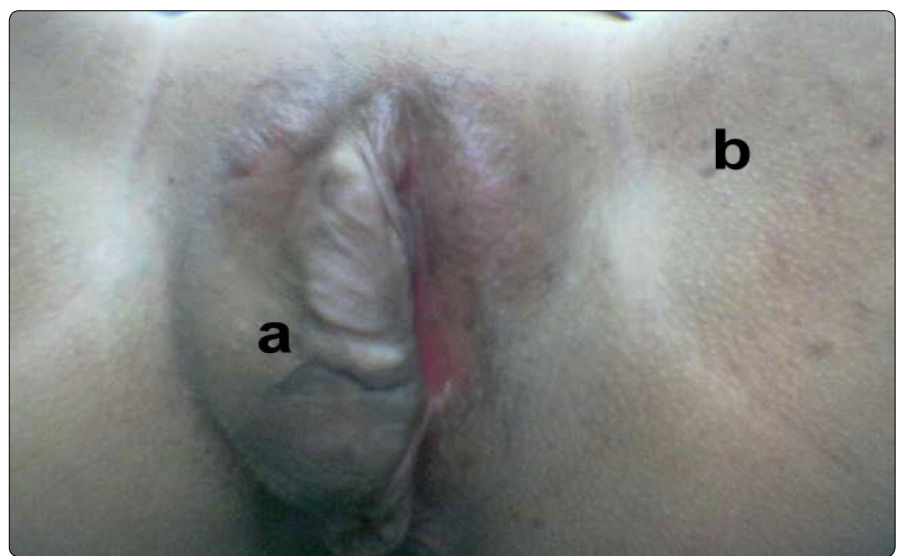

Figure 1a. Right Vulval swelling due to plexiform neurofibroma of the diffuse type, b. inguinal freckling
Based on the previous diagnosis of plexiform neurofibromatosis, decision for an extended excision of the vulval swelling with a safety margin was taken. At the operation the tissues were found very vascular and the swelling was excised with a safety margin with extension to the labial fat and perianal area.

\section{Pathologic Findings}

The specimen consisted of a grayish white mass of $8 \times 4$ $\mathrm{cm}$ size, firm in consistency with a covering ellipse of corrugated skin, with a whitish whorly cut section. Microscopically, within the dermis, there was a poorly demarcated nodule composed of numerous anatomizing fascicles of Schwann cells, that was separated by fibrous bundles and extended among and replacing skin appendages. Structures resembling pacinian corpuscles were also present. Some of the anatomizing fascicles of Schwann cells showed myxoid areas, whereas others exhibited fibrosis. Areas with a diffuse pattern showing elongated Schwann cells with serpentine, wavy nuclei were seen as well in Figures $2 a \& 2 b$.

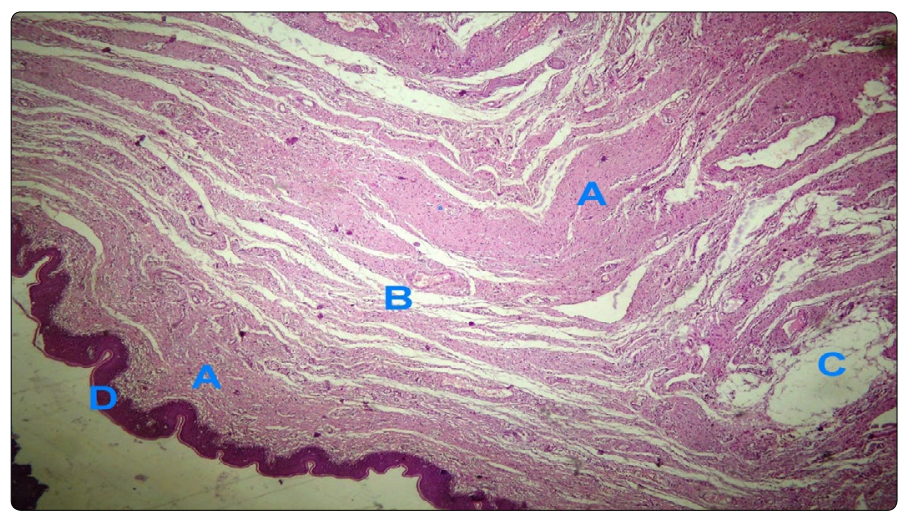

Figure 2a. Diffuse pattern showing elongated Schwann cells with serpentine, wavy nuclei

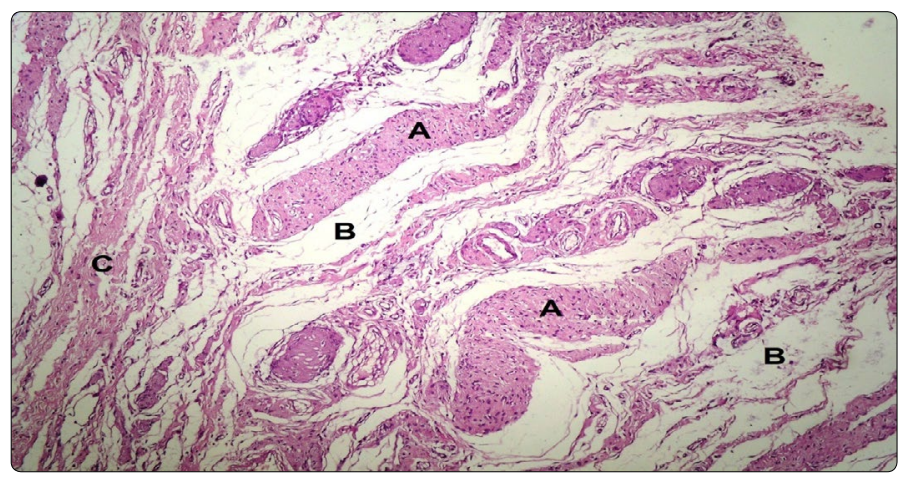

Figure 2b. Diffuse pattern showing elongated Schwann cells with serpentine, wavy nuclei

Immunohistochemistry with streptavidin-biotinperoxidase is positive for protein S-100 antibodies, where S-100 protein immunostain highlighted the fascicles of Schwann cells with areas exhibiting a diffuse pattern, confirming the diagnosis of plexiform neurofibroma of the vulva (Figure 3). 


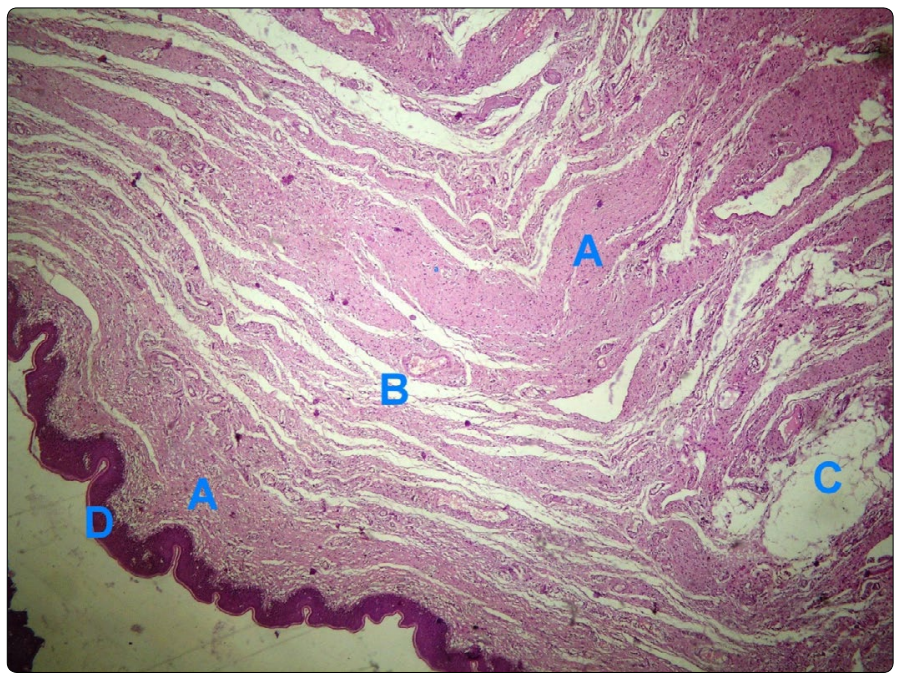

Figure 3. A. Anastomosing fascicles of Schwann cells, B. Fibrous Bundles, C. Myxoid areas.

D. Vulval skin $H \& E, x 100$

\section{Discussion}

Genitourinary tract affection with NF1 in girls is rare where most of it is presenting as clitoral hypertrophy. Of the 31 cases recorded with Genitourinary neurofibroma in NF1, in 17 (57\%), the neurofibroma only involved the clitoris; in 6 (20\%), the tumor also involved the bladder (in 2, the ureters also were involved); and in $8(27 \%)$, the neurofibroma also involved the labia majora [7,11-13].

In the present case, we describe a labium majus involvement with plexiform neurofibroma of diffuse type in a child as a primary presentation of NF1 without any other clinical manifestations of the disease nor clitoral involvement which is extremely rare [7].

Neurofibromatosis is a neuroectodermal heterogeneous disease originating from the neural crest cells and is of two types: NF1 (von Recklinghausen) and NF2 (acoustic neuroma). The neurofibromatosis type 1 is an autosomal dominant disease of incidence of 1 in 3,500 live births with spontaneous mutations in half of all cases $[14,15]$. It is caused by a gene on chromosome 17, where its protein product (neurofibromin), control cell growth and differentiation by tumor suppressor action.

Mutation in the neurofibromatosis type 1 gene of neural crest- derived cells is the molecular basis of genetic mosaicism, and functional loss of neurofibromin in Schwann cells or fibroblasts, determine the occurrence of neurofibromas or pigmentary changes respectively [16]. Early mutations cause a generalized disease whereas mutations occurring late in embryogenesis give rise to an affected single region or organ (localized disease) [16].

Genetic counseling is the first step in the management of NF1, where if a parent is affected, the risk of NF for each pregnancy is $50 \%$ and annual examinations in a multidisciplinary clinic in the first 10 years of life are recommended [17]. The diagnosis of most of cases of NF1 is based on clinical manifestations in spite of great advances in genetic testing that diagnose as many as $95 \%$ of cases. The prenatal diagnosis and diagnosis in patients with equivocal physical signs as in a child with cafe au lait patches only could be done with DNA analysis [17,18].

To diagnose NF1, presence of 2 or more of the following criteria is needed; 6 or more café au lait patches, axillary or inguinal freckling, 2 or more cutaneous neurofibromas, 1 plexiform neurofibroma, characteristic bonylesions (pseudarthrosis, sphenoid wing hypoplasia), an optic glioma, 2 or more iris Lisch nodules, or a first-degree relative with NF1 [19]. The diagnosis could be made at birth, while in others observation for a few years is needed for the appearance of additional criteria. Some patients have very mild manifestations, whereas others are severely affected. Caféau-lait spots and skin neurofibromas occur in $95 \%$ of patients or more, whereas other criteria occur in less than $1 \%$ of cases, and consistency in manifestations within a pedigree is not a rule [20].

Morbidity of NF1 could be in the form of disfiguring cutaneous lesions, visual or hearing affection, pain, seizures, spinal cord compression, bowel or urinary bladder complications, Psychological stress. However, some of these complications are infrequent, but psychosocial problems remain a significant problem. Mental retardation, dysmorphic facial features, and to a lesser extent early tumor burden is more common in patients with large gene deletions, but, as yet, there is no clear genotype/ phenotype correlation [21]. The increased mortality in young adults could be attributed to the increased incidence of cardiac diseases and malignant tumors [22].

Cancer is $3 \%$ more in patients with neurofibromatosis type 1 (NF1) than in general population with increased frequency of unusual tumors as Carcinoid, pheochromocytoma, brain tumors, chronic myeloid leukemia, and malignant peripheral nerve sheath tumors [23]. Other tumors such as breast, lung, kidney and colon, occurs less frequently than in the normal population [24].

Neurofibromas, the hallmark of NF1, are tumors of the autonomic peripheral nerves (Schwann cells) and rarely involve organs in the urogenital system and may be found in essentially any site, including the gastrointestinal tract, blood vessels, heart, and larynx [15]. Plexiform neurofibroma (both nodular and diffuse type) occurs in only 5 percent of patients with NF1 [25]. Diffuse plexiform neurofibroma, as in the present case, also known as elephantiasis neurofibromatosa has an overgrowth of epidermal and subcutaneous tissue associated with a wrinkled and pendulous appearance, poorly circumscribed, infiltrate along connective tissue septae, and envelop normal structures with uniform fibrillary collagen bundles [26]. There is an increased risk of malignant transformation (from 12 to $29 \%$ ) in these neurofibromas, that necessitate follow-up clinically and with serial imaging with tumor excision if the mass increases suddenly. Other complications include bleeding from trauma, neurological, limb movement, and psychological problems.

Surgical excision of cutaneous neurofibromas is the only treatment option for most of the lesions in NF1 and is indicated if they are causing discomfort or are visible and stigmatizing or compromise organ function. Total excision of a plexiform 
neurofibroma is difficult due to finger-like fronds that insinuate themselves into adjacent tissues which explain the local recurrence in the present case, and so clinical follow-up is required every 6 months during the first 2 years and then annually. They are often vascular causing substantial blood loss during removal and so careful imaging of tumors is essential to define its boundaries and evaluate its vascular supply $[27,28]$. Plexiform neurofibroma is not sensitive to chemotherapy and radiotherapy should be limited to malignant tumors because it can stimulate the growth of plexiform lesions.

\section{Conclusion}

In conclusion, despite its rarity, physicians should consider neurofibroma as a differential diagnosis of a vulval swelling, especially in patients who have other clinical manifestations of neurofibromatosis, or with family history of the disease, that might help in the management by wide excision of the mass with a safety margin at the primary surgery to prevent its recurrence.

\section{References}

1. Sengupta SP. Tumours and cysts. In: Long and Short cases in Surgery. 1st Edition, New Centre Book Agency Publications, Calcutta. 1996; 39-75.

2. Diehl SR, Boehnke M, Erickson RP, Ploughman LM, Seiler KA, et al. A refined genetic map of the region of chromosome 17 surrounding the von Recklinghausen neurofibromatosis (NFI) gene. Am J Hum Genet. 1989; 44(1): 33-37.

3. D'Agostina AN, Soule EH, Miller RH. Sarcomas of the peripheral nerves and somatic soft tissues associated with multiple neurofibromatosis (von Recklinghausen's disease). Cancer.1963; 16: 1015-1027.

4. Patil S, Chamberlain RS. Neoplasms Associated with Germline and Somatic NF1 Gene Mutations. Oncologist. 2012; 17: 101-116. doi: 10.1634/ theoncologist.2010-0181

5. Ruggieri M, Huson SM. The clinical and diagnostic implications of mosaicism in the neurofibromatoses. Neurology. 2001; 56(11): 1433-1443.

6. Wozniak W, Karwacki MW. Is "watchful waiting" superior to surgery in children with neurofibromatosis type 1 presenting with extracranial and extramedullary tumor mass at diagnosis?. Childs Nerv Syst. 2008; 24(12): 1431-1436. doi: 10.1007/s00381-008-0668-7

7. Pascual Cl, Lopez PP, Savasta S, Lopez SC, Lago CM, et al. Neurofibromatosis type 1 with external genitalia involvement presentation of 4 patients. $J$ Pediatr Surg. 2008; 43(11): 1998-2003. doi: 10.1016/j.jpedsurg.2008.01.074

8. Dogra BB, Ahmed S, Kandari A, Virmani R. Plexiform neurofibromatosis of vulva. Int J Res Med Sci. 2014; 2(4): 1771-1773. doi: 10.5455/2320-6012. ijrms201411109

9. Packer RJ, Rosser T. Therapy for plexiform neurofibromas in children with neurofibromatosis 1: an overview. J Child Neurol. 2002; 17(8): 638-41. doi: $10.1177 / 088307380201700816$

10. Blickstein I, Lurie $\mathrm{S}$. The gynaecological problems of neurofibromatosis. Aust N Z J Obstet Gynaecol. 1990; 30(4): 380-382. doi: 10.1111/j.1479-828X.1990. tb02036.x
11. Thomas WJ, Bevan HE, Hooper DG, Downey EJ. Malignant schwannoma of the clitoris in a 1-year-old child. Cancer. 1989; 63 (11):2216-9.

12. Kaefer $M$, Adams MC, Rinck RC, Keating MA. Principles in management of complex pediatric genitourinary plexiform neurofibroma. Urology. 1997; 49(6): 936-40.

13. Griebel ML, Redman JF, Kemp SF, Elders MJ. Hypertrophy of clitoral hood: presenting sign of neurofibromatosis in female child. Urology. 1991; 37(4): 337-9.

14. Nasir AA, Abdur-Rahman LO, Ibrahim KO, Adegoke MA, Afolabi JK, and AdeniranJO. Genitourinary Plexiform Neurofibroma Mimicking Sacrococcygeal Teratoma. J Surg Tech Case Rep. 2012; 4(1): 50-52. doi: 10.4103/2006-8808.100356

15. Weiss SW, Goldblum JR. Enzinger and Weiss's Soft Tissue Tumors. 4th ed. St Louis, Mo: Mosby Inc; 2001

16. Redlick FP, Shaw JC. Segmental neurofibromatosis follows blaschko's lines or dermatomes depending on the cell line affected: Case report and literature review.J Cutan Med Surg. 2004; 8(5):353-6. doi: 10.1177/120347540400800505

17. Kathry N N. Clinical aspects of neurofibromatosis I, Nurth European Journal of Paediatric Neurology 1998; 2(5): 223-231

18. Tsang $E$, Birch $P$, Friedman JM. Valuing gene testing in children with possible neurofibromatosis1. Clin Genet. 2012; 82(6): 591-3. doi: 10.1111/j.1399-0004.2011.01801.x

19. Mulvihill JJ, Parry DM, Sherman JL, Pikus A, Kaiser-Kupfer MI, Eldridge R. Neurofibromatosis 1 (Recklinghausen disease) and neurofibromatosis 2 (bilateral acoustic neurofibromatosis): an update. Ann Intern Med. 1990; 113(1): 39-52.

20. Carey JC, Laud JM, Hall BD. Penetrance and variability of neurofibromatosis: a genetic study of 60 families. Birth Defects Orig. Artic Ser.1979; 15(5B): 271-281.

21. Tonsgard JH, Yelavarthi KK, Cushner S, Short MP, Lindgren V. Do NF1 gene deletions result in a characteristic phenotype? Am J Med Genet. 1997; 73(1): 80-86. doi: 10.1002/(SICI)1096-8628(19971128)73:1

22. Friedman JM, Arbiser J, Epstein JA, Gutmann DH, Huot SJ, Lin AE et al. Cardiovascular disease in neurofibromatosis 1: report of the NF1 cardiovascular task force. Genet Med. 2002; 4 (3): 105-11.

23. Joshua TD, Janice MK, Jonathan WW, Gibbs R A, Borch R F, Tainsky MA et al. Molecular targets for emerging anti-tumor therapies for neurofibromatosis type 1. biochemical pharmacology. 2006; 72: 1485-1492.

24. Sorensen SA, Mulvihill JJ, Nielsen A. Long-term follow-up of von Recklinghausen neurofibromatosis. Survival and malignant neoplasms. $N$ EnglJmed. 1986;314(16):1010-1015. doi:10.1056/NEJM198604173141603

25. Pivnick EK, Riccardi VM. The Neurofibromatoses. In: Freedberg IM, Eisen AZ,Wolff K, Austen KF, Goldsmith LA, Kartz SI, Fitzpatrick TB. Fitzpatrick's Dermatology in General Medicine. New York: Mc graw Hill. 1999; 2152-58.

26. Harper Jl. Genetics and genodermatoses. In: Champion RH, Burton JL, Burns DA, Breathnach SM editors Rook/Wilkinson/Ebling. Text book of Dermatology. 6th ed. Oxford: Blackwell Science. 1998; 378-84.

27. Littlewood AH, Stilwell JH. The vascular features of plexiform neurofibroma with some observations on the importance of pre-operative angiography and the value of pre-operative intra-arterial embolization. Br J Plast Surg. 1983; 36(4): 501-506.

28. Tonsgard JH, ShortMP, Yamini B, etal: Surgical treatment of neurofibromatosis, in Schmidek HH, Roberts DW(eds): Schmidek and Sweet's Operative Neurosurgical Techniques, 5th Edition. Amsterdam 2006; 1: 968-974. 